\title{
THE SPINAL INJURIES UNIT AND REHABILITATION
}

\author{
By Thomas M. GregG, M.D., F.R.C.P.I. \\ National Medical Rehabilitation Centre, Dublin
}

THERE are 3 million persons in Southern Ireland with $I \cdot I$ million of working age available for work including 90000 unemployed. There are 130000 of this age group unfit for work. Some 30000 of these have short-term illnesses obtaining weekly insurance certificates, leaving 100000 with long-term or permanent disability. There are 330000 persons over 65 years with a much higher incidence of disability.

Disability from spinal cord involvement forms a very small section of this group. We admit roo cases of spinal injury each year. This would include about 50 with spinal cord damage and 50 with unstable fractures without paralysis which are best cared for in a spinal injuries unit. There are about 750 cases of paraplegia or tetraplegia from spinal injury in the community. There are nearly as many from spina bifida following early surgery and probably about another I 500 from severe multiple sclerosis and other causes. This group though small in the general statistics of disabled provide the main long-term problem to the general hospital and community services. They also provide the image in the public mind of the disabled person and draw the support from the community for work for all handicapped persons.

The main purpose of the spinal unit is to provide a high standard of treatment and rehabilitation in the acute stage and follow-up throughout life of those with spinal injury and paraplegia. In Ireland the spinal injury unit is in the National Medical Rehabilitation Centre. The spinal unit provides an experienced and skilled team of doctors, nurses and paramedical workers and the only setting in which such cases can be safely and effectively managed.

The grouping in the unit and continuity of supervision provides the opportunity to monitor and study the techniques of diagnosis and treatment. It has led to increased medical knowledge. Much original work in the care of the neurogenic bladder has come from the spinal unit. Techniques of prevention and treatment of pressure sores have been developed. Patterns of care of the bowel have been formed. Respiratory, vascular, sexual and other problems arising in paraplegia have been studied in such units bringing forward the limits of medical understanding.

Such problems which present so acutely in the spinal unit are in fact the main problems of many severely physically disabled in the health service. It is the natural location for undergraduate and postgraduate training in rehabilitation medicine. It is also the training ground for specialised rehabilitation nursing-one of the major developing nursing specialities. In our unit we run a 6-month training course for nurses recognised by the Nursing Board and the Department of Health and those with the qualification are entitled to an addition to the ordinary salary in the health service. The training includes that of the care of skin, bladder and bowel and general nursing techniques. Insight is given into training in A.D.L., mobility and the social and vocational problems of the handicapped. Understanding morale and motivation are important. Considerable pride in the value 
of such work results and the nurses return to general hospitals, long-term homes, geriatric centres and to the community services with knowledge and skills that improve the standards of the health services. The knowledge gained is equally relevant to the severe multiple sclerosis sufferer, the hemiplegic, the severe arthritic, those with Parkinson's disease and others with physical disability or incontinence.

In Ireland we have a district or public health nurse in each small community area. All of these spend a week in the rehabilitation centre as part of their training and return for refresher visits. One section of their examination is on problems of physical disability as seen in the unit. This means that the spinal injury case returning home will have a nurse near by with knowledge of his problem. The patient and his near relative are trained in his care in the centre. The paraplegic is readmitted once or twice annually for review. This results in a comprehensive care and support for life.

Knowledge of spinal injuries is important in first aid and in the ambulance service. Here again every ambulance man in my country attends the spinal injury unit during his training course. He is instructed in the selection of those cases who need special care and in their transfer safely to the local hospital. The local hospital informs the spinal unit and they are flown in by helicopter with a trained team from the spinal unit within hours of their accident.

The public is now conscious as a result of this work of the needs of access for the disabled, in particular the wheelchair case. The health authorities adapt houses and the need for providing access to all new public buildings and areas to which the public have access is appreciated. New building regulations are being introduced to enforce this. Grants are available towards motorised transport for those unable to use buses and trains.

Vocational assessment for the disabled was pioneered in Ireland in the National Medical Rehabilitation Centre in association with the spinal injury and other services. There are now grants for vocational training and placement officers in each community care area throughout the country employed by the National Rehabilitation Board which is directly related to the Centre.

Sport plays an important part in the rehabilitation of the paraplegic and has developed from the Centre. Courses of training for instructors in sports for the physically handicapped are based at the Centre. A voluntary association-The Irish Wheelchair Association-started by the paraplegic patients sends teams of sportsmen to the Stoke Mandeville International Games. It also provides holidays and social outlets for the very severely disabled.

The number of paraplegics from spinal injury is small when viewed against the overall number of handicapped persons. The value of the spinal injury unit in addition to giving life to this number spreads far and wide in benefiting disabled persons throughout the community. It influences the approach to disabled in a country. The unit in Ireland followed the inspiration of Sir Ludwig Guttman and the work at Stoke Mandeville. Sir Ludwig visited and influenced our policy makers. He arranged for training of doctors, nurses and therapists in Stoke Mandeville to start our unit and we have progressed from there. We owe him and his colleagues much.

'Ad multos annos.' 